\title{
AIRLINE EFFICIENCY AND AIR PASSENGER TRIP CIRCUITY TREND
}

\author{
Al Meilus, Federal Aviation Administration, Washington, DC
}

\begin{abstract}
This paper addresses how airline industry consolidation and network realignments affect passenger trip efficiency as measured by trip circuity (ratio of passenger distance flown to direct distance). Over the last 20 years, airlines have dropped many point-to-point markets in favor of flowing passengers through large hub airports. Despite this trend, the portion of passenger origin to destination itineraries satisfied by direct flights has generally been increasing in the US. All else being equal, this trend benefits passengers, air carriers, and the environment, because it means that passengers spend less time traveling; carriers are transporting their passengers more efficiently to their destinations more frequently on direct routes; and there is less fuel required to meet travel demand. However, significant structural changes in the airline industry have coincided with discontinuities in this trend. This paper explores how some of the industry's structural changes have affected this trend, and how this trend is currently being affected.
\end{abstract}

\section{Connecting vs. Direct Air Travel Itineraries and Trip Circuity}

This paper utilized DOT DB1B Market data [1] to analyze passenger trip efficiency by analyzing the ratio of passenger distance flown to direct distance, or trip circuity.

The DB1B Market table contains directional market characteristics of each domestic itinerary from the Origin and Destination Survey. The table includes elements like reporting carrier, origin and destination airport, number of market coupons, market miles flown, and non-stop market miles (great circle distance). It is important to note that in this data set, market distance is not necessarily all traveled by air. Some of the reported markets include a mix of air and surface travel. For the purposes of this analysis, we use only the records where the miles flown are the same as the market distance.

Circuity can be affected by the relative frequency of connecting passenger itineraries (compared to non-stop itineraries), as well as by how much the total distance traveled on connecting itineraries differ from the great circle distances for each origin-destination (OD) market. The DB1B data set shows that the percentage of connecting itineraries has generally been decreasing for the last 20 year. Figure 1 shows that in 1993, about $37 \%$ of passengers traveled with at least one connection. By 2012 that ratio dropped to about $32 \%$. This suggests that air carrier networks are generally doing an increasingly better job of delivering passengers from their points of origin to their destinations without needing to route them on connecting flights.

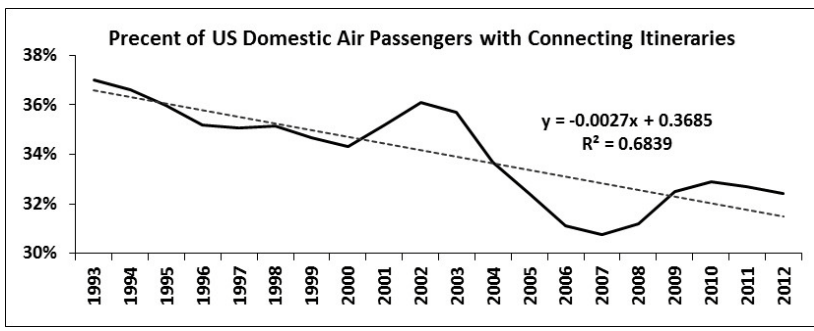

\section{Figure 1. Percent of US Domestic Air Travel Passengers with Connecting Itineraries}

The decreasing rate of passengers traveling on connecting itineraries helps reduce passenger trip circuity. Figure $2 \mathrm{a}$ shows that air passenger trip circuity has generally been declining for the last 20 years, but Figure $2 \mathrm{~b}$ shows that air passenger trip circuity for US passengers traveling on two or more connecting flights has been strongly increasing for the last 20 years.

There has been a noticeable increase circuity since 2008 overall which coincides with the increase in percent of passengers making connecting flights in that same time period as shown in Figure 1. The increases in passenger trip circuity also coincide with significant reductions of operations at some of the major hubs in the US. This paper explores how circuity is affected when carriers change their network structure. 


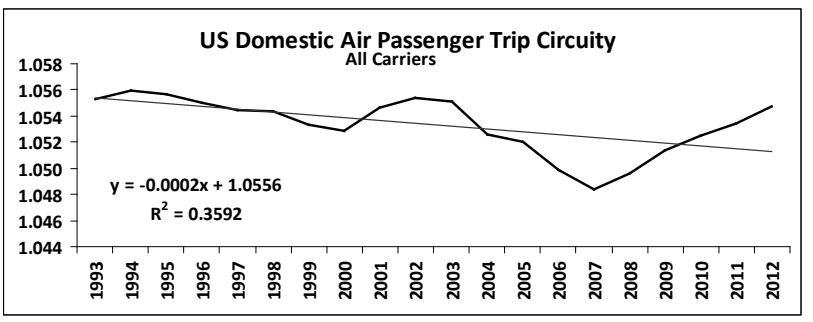

\section{Figure 2a. Circuity for US Domestic Air Travel Passengers}

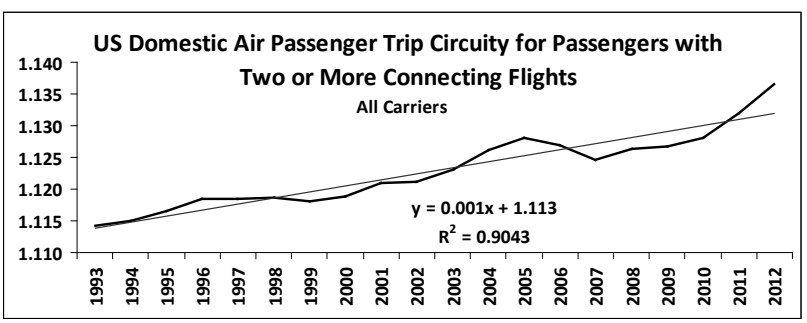

\section{Figure 2b. Circuity for US Domestic Air Travel Passengers with Two or More Connecting Flights}

There are a number of factors that can affect this trend other than just airline network structures. For example, there has been an increasing trend of people leaving rural areas in preference of urban areas [2] [3]. For the purposes of this paper, the air carriers get full credit for aligning their networks with where people are and where they want to go, whether through serendipity or deliberate network planning. However, the decreasing trend of connecting itineraries has not been monotonic. Figure 1 shows that there are two significant disruptions. The two significant disruptions occurred from 2000 through 2002 and 2008 through 2010 where the data jumps above the long-term trend line. Interestingly, these years coincide with airline merger events which also coincide with the significant reduction in operations at a few major hubs. The 2002 event corresponds to American Airlines de-hubbing St Louis International airport (STL) after acquiring TWA. The 2010 event coincides with the merger of Delta and Northwest and the de-hubbing of Delta's hub at Cincinnati (CVG).

\section{US Airline History}

Figure 3 (source: Innovata schedule data) shows the last ten years of scheduled operations in the US by carrier, with some of the major carriers identified.
A number of mergers are noticeable in the Figure: US and HP, DL and NW, UA and CO.

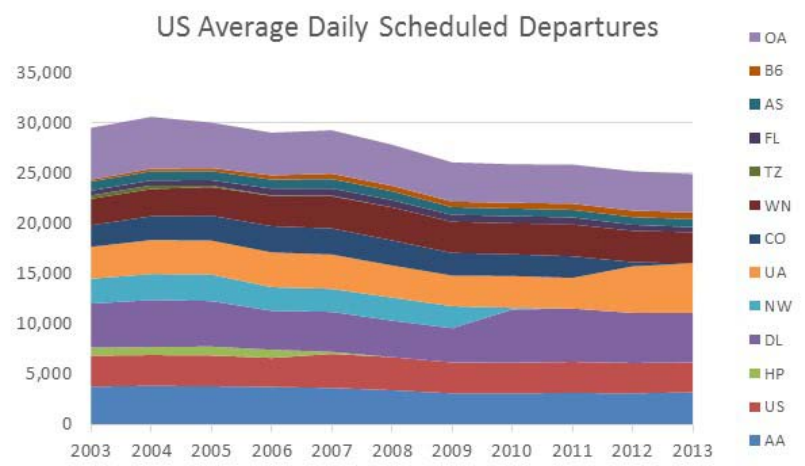

Figure 3. Daily US Scheduled Departures

Unfortunately, the historic schedule data currently available does not extend beyond 2003. The following list provides a timeline of some of the major airline mergers, acquisitions and shut downs that occurred during the 20 years covered by the DB1B data set [4].

1993: Southwest acquires Morris Air

1997: ValuJet Airways merges with AirWays Corp., and becomes AirTran Airways

1999: American buys Reno Airways

2001: American buys TWA

2005: US Airways merges with American West Airlines

2008: Delta merges with Northwest

2010: United merges with Continental

2011: Southwest merges with Air Tran

\section{3: American merges with US Airways}

It is interesting to note that not all mergers have led to disruptions in the trip circuity trend. In addition, while it may appear that mergers among air carriers is a recent phenomenon, the lineage listed below for Delta Air Lines, as an example, demonstrates that mergers have been an integral part of US airline history [5]:

Chicago and Southern Air Lines (formed in 1933, merged into Delta in 1953)

Northeast Airlines (formed in 1931, merged into Delta in August 1972) 
Northwest Airlines (formed in 1926, merged into Delta in 2010. Also known as Northwest Orient Airlines from 1950-1989)

Republic Airlines (formed in 1979, merged into Northwest Airlines in 1986)

Hughes Airwest (formed in 1968 as Air West, name change to Hughes Airwest in 1970, merged into Republic Airlines in 1980)

Bonanza Air Lines (formed in 1945, merged into Hughes Airwest (Air West) in 1968)

Pacific Air Lines (formed in 1941, merged into Hughes Airwest (Air West) in 1968)

West Coast Airlines (formed in 1941, merged into Hughes Airwest (Air West) in 1968)

North Central Airlines (formed in 1946, merged into Republic Airlines in 1979)

Southern Airways (formed in 1944, merged into Republic Airlines in 1979)

Pan American World Airways (formed in 1927, portions of which were merged into Delta in 1991)

Atlantic, Gulf, and Caribbean Airways (formed in 1927, merged into Pan American World Airways in 1928)

American Overseas Airlines (formed in 1937, merged into Pan American World Airways in 1950)

Aviation Corporation of the Americas/American International Airways (formed in 1926, merged into Pan American World Airways in 1928)

National Airlines (formed in 1934, merged into Pan American World Airways in 1980)

Western Airlines (formed in 1925, merged into Delta in 1987)

Standard Air Lines (formed in 1927, merged into Western Airlines in 1930)

Delta's lineage is by no means unique among today's large carriers. American Airlines Group has merged with many carriers since its formation in 1930, which itself happened by merging 80 different carriers together. The ancestors of today's American include parts or all of Trans Caribbean Airways, Air
California, Trans World Airlines (TWA) and Reno Air. Today's United Airlines also has a long list of predecessor carriers. Based on the history of airline mergers and acquisitions, it is probably safe to say that the mergers that occurred in the last 20 years, while increasing larger in scale, are not out of character for the airline industry.

\section{Operations and Circuity at Busiest US Airports}

Our initial review of the data in aggregate suggests that mergers and more specifically, hub closures cause passengers to travel less efficiently in some cases, for at least some time, until the network of the merged carriers are realigned and harmonized to adjust for hub closures. This paper will review the circuity of the largest US carriers over the last 20 years to see if the above conjecture can be substantiated.

Looking at the last 20 years of operations at the individual airport level [6], we can see how operations at some hubs have been built up, while operations at other airports have declined. The next two Figures, 4a and 4b, show the 20 year trend for the top 15 airports and the next 15 airports in the US.

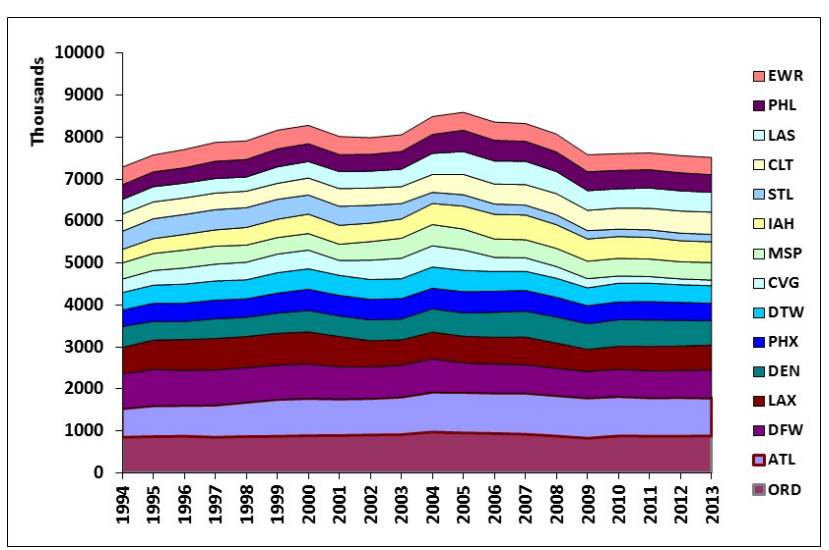

Figure 4a. Number of Operations at the Top 15 US Airports 


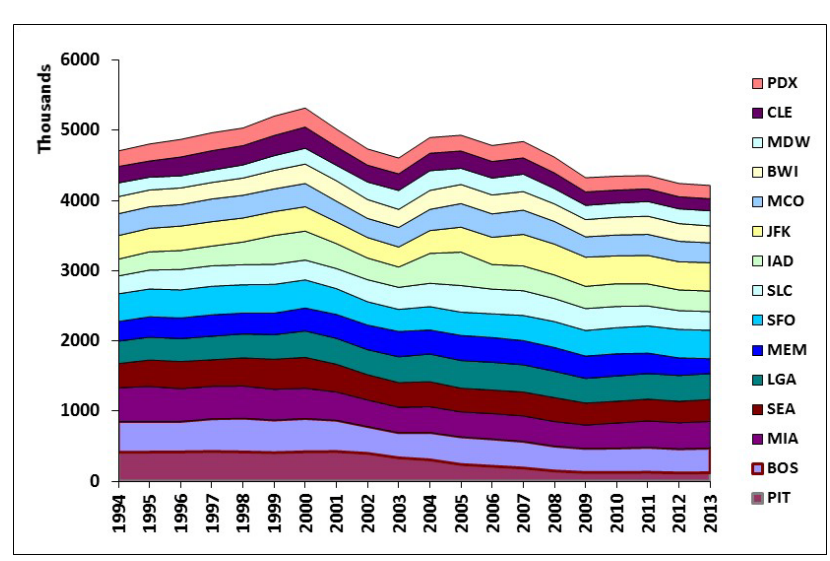

\section{Figure 4b. Number of Operations at the Next 15 US Airports}

Figures $4 \mathrm{a}$ and $4 \mathrm{~b}$ display a number of interesting characteristics about the airline industry. We can see that the number of operations in the top tier airports have fluctuated with the economy, and are most recently about 3\% higher than 20 years ago, while the number of operations in the next 15 airports has declined more than $10 \%$ in the last 20 years. In total, the number of operations reported in OPSNET for the ASPM 77 airports has declined 5.7\% from 1994 to 2013. In addition, we can see from figures 4a and $4 \mathrm{~b}$ that much of the decline in the number of operations can be attributed to a few of the once-large hubs. One striking example is the significant decline at CVG, which at its peak in 2004 was the 7th busiest airport in the US based on annual operations, but by 2013 has fallen to 40th following a 74\% decline in annual operations. Other airports that have experienced sharp declines in operations include PIT which is down $72 \%$ from its peak and STL which is down $63 \%$ from its peak. Interestingly, the peak year of operations for both PIT and STL was 1997. In 2013 , only a few large airports were operating at or near their historic peak operations of the last 20 years. CLT and SFO are two of the large airports whose operations were within $1 \%$ of their historic peak number of operations. DCA, which is not shown in figures $4 \mathrm{a}$ or $4 \mathrm{~b}$ also operated at its historic peak in 2013. In addition, figures $4 \mathrm{a}$ and $4 \mathrm{~b}$ illustrate the dehubbing effect on the number of operations at CVG, PIT and STL.

At its peak in 1997, STL was the 5th busiest airport in the US based on the number of annual operations. In 2013, STL ranked as the 31th busiest airport. The largest reductions at STL took place from 2000 through 2004 when American cut back operations there after it acquired TWA. In 2013, operations at STL were only $37 \%$ of what they were in 1997. From 1994 to 1999 AA's average trip circuity dropped from 1.059 to 1.045 ; however, since then AA's circuity has risen somewhat, registering 1.050 in 2012.

The largest reductions at CVG took place from 2008 to 2010 when Delta reduced its operations there. From 1994 to 1999 DL's average trip circuity dropped from 1.077 to 1.061 ; however, since then DL's circuity has risen slightly, registering 1.066 in 2012. Coinciding with the reduction of operations at CVG was the reduction of flying performed by DL's regional partner, Comair, which has recently ceased operating. Comair's center of operations was at CVG.

At its peak in 1997, PIT was the 13th busiest airport in the US based on the number of annual operations. In 2013, PIT ranked as the 45th busiest airport. The largest reductions at PIT took place from 2002 through 2004 when US Airways cut back its operations there. In 2013, operations at PIT were only $28 \%$ of what they were in 1997 . Curiously, US's average trip circuity has generally been increasing over the last 20 years. In addition, US's circuity actually decreased with the initial reduction of operations at PIT from 2002 with a circuity of 1.062 to 2004 with a circuity of 1.054 . Since 2005, US Airways circuity has been rising, registering 1.074 in 2012. The reason for US Airways circuity increasing in recent years is partly due to the location and growth of its busiest hub, CLT. As one of its most profitable hubs, US Airways has been focusing its growth at CLT since 2009. Figure 5 shows CLT passenger trip circuity with an increasing trend over time.

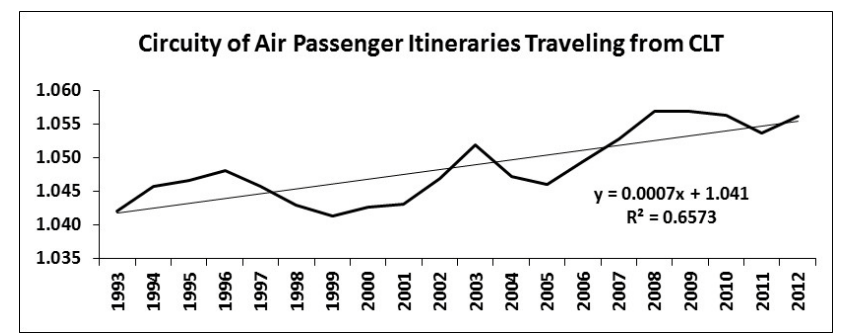

\section{Figure 5. Circuity of Air Travel Passengers} Traveling From CLT

These examples have shown that circuity is significantly affected at the individual airport level as well as nationally by large carrier network changes. 


\section{Trip Circuity for Passengers from Small Communities Compared to Trip Circuity for Passengers from Large Airports}

Concerned that communities with relatively lower traffic levels could lose service entirely, Congress established the Essential Air Service (EAS) program. The EAS program provides a Federal subsidy to ensure that smaller communities retain a link to the national air transportation system [7]. Because of their relatively small size, EAS communities rely heavily on connecting flights to reach national destinations. In fact, historically, $80 \%$ to $90 \%$ of EAS air passengers have needed to travel on two or more segments to reach their destinations as compared to an average of only $30 \%$ to $40 \%$ nationally. Figure 6 shows the increasing trend of EAS passenger trip circuity over the last 20 years. It is interesting to note that the circuity rate for EAS passengers is not only increasing, but it is significantly higher than the national average circuity. In fact, EAS trip circuity is higher than the national average for passengers with two or more connecting flights. Nationally air passenger trip circuity has averaged about 1.05, while EAS passenger trip circuity has averaged about 1.16 over the last 20 years.

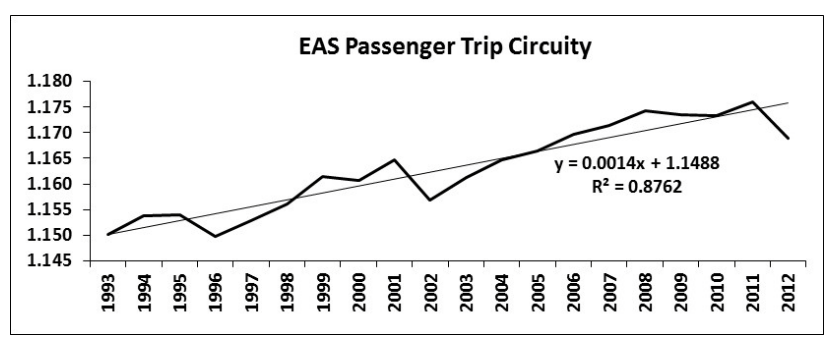

Figure 6. EAS Passenger Trip Circuity

Figures 7 shows that circuity for passengers traveling from and to an ASPM77 airport had generally been declining until 2007, when it hit a 5year period of reversing the reductions in circuity achieved in the previous 15 years. As we would expect, circuity for travel among the ASPM77 airports of about 1.037 is still lower than the national average.

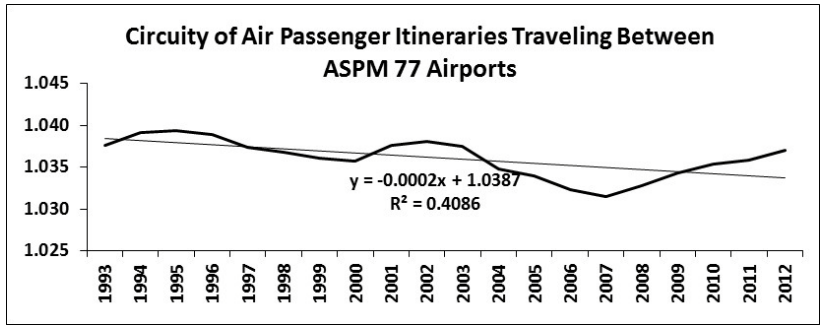

Figure 7. Circuity of Air Passenger Itineraries Traveling Between ASPM 77 Airports

In figure 8, we can see that the busiest airports in the US (ATL, ORD, DFW, LAX and DEN) are driving the overall trend in the declining rate of circuity nationally, despite a reverse of course in the rest of the country. Circuity among the busiest airports has declined from 1.032 in 1993 to 1.024 in 2012.

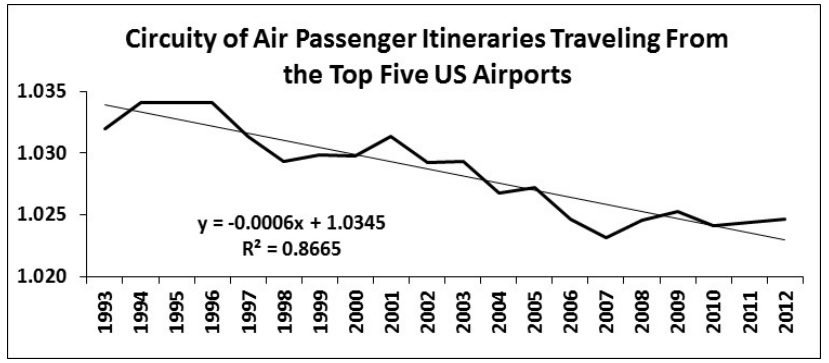

Figure 8. Circuity of Air Passenger Itineraries Traveling from the Five Busiest US Airports

\section{National Carrier Networks}

Although as we saw in Figure 2, the most recent measures of circuity were increasing, economic pressures will likely push the airline industry to resume its long-run trend of declining circuity. There are inherent challenges to reducing circuity. The air carriers need to balance the efficiencies of their route networks, including their code share and alliance partners, with where their passengers want to fly. As mentioned earlier, mergers and restructuring have historically been an integral part of the US aviation industry. The industry will likely continue to evolve through corporate mergers and hub adjustments. Current changes, which are not fully reflected in the data sets, include Delta's de-hubbing at MEM and United sharply reducing service at CLE. Additional network changes may occur as a result of United, American, Delta and Southwest further adjusting their respective post-merger networks. Although 
these carriers are fully national in their scope of market coverage, the number of hubs and large focus airports where they operate varies significantly.

Combined AA/US combined has 11 airports in the US with 90 or more scheduled peak day departures in 2013 (DFW, CLT, ORD, PHL, MIA, PHX, DCA, LAX, LGA, BOS and JFK).

DL has 9 airports in the US with 90 or more schedule peak day departures in 2013 (ATL, DTW, MSP, SLC, LGA, JFK, LAX, CVG and MEM). UA has 8 airports in the US with 90 or more schedule peak day departures in 2013 (ORD, IAH, EWR, DEN, SFO, IAD, LAX and CLE).

Combined WN/FL has 13 airports in the US with 90 or more schedule peak day departures in 2013 (MDW, BWI, LAS, ATL, PHX, DEN, HOU, MCO, DAL, LAX, OAK, STL and SAN).

We already know from press releases that of the key airports listed for these carriers, operations at CVG, MEM and CLE are going being reduced. On the growth side, we know that Delta is increasing its operations at SEA which is not currently on their list.

\section{Conclusion}

While we can be certain the US air carrier networks will continue to evolve, it remains to be seen how air carrier networks will adjust to passenger demand and economic pressures. Delta is shedding two of its hubs in the Midwest, possibly gaining SEA on the West coast bringing its hub count to 7 or 8 . UA's hub count will be at 7 as CLE drops off its list. The newly combined AA/US may not need to continue to operate full schedules at the 11 listed airports as it has been, unless AA adopts a less banked hub structure like WN with its list of large operations at 13 airports throughout the country.

Future mergers may not all be as big as the most recent ones that have successively created the next largest carrier in the world, but mergers are likely to continue. As airlines continue to merge, their networks will continue to evolve and be shaped by economic and market forces. Based on historic trends, US airline network changes will likely continue to push the national average for air passenger trip circuity downward, with large air carriers relying on a few select large hub airports.

\section{Future Work}

It would be interesting to study how national carriers determine the optimal number of hubs for their networks. While mergers create larger carriers and networks, not all of the acquired hubs need to be retained to provide national network coverage. Airlines are businesses that need to make economically sound strategic decisions. The shapes of their networks are a key factor influencing their corporate revenue as well as their costs.

\section{References}

[1] TranStats, US Department of Transportation, Bureau of Transportation Statistics:http://www.transtats.bts.gov/Fields.asp?Tab le_ID=247, last accessed March 17, 2014

[2] Lambert, Lisa, Mar 26, 2012, Rueters, More Americans move to cities in past decade-Census http://www.reuters.com/article/2012/03/26/usa-citiespopulation-idUSL2E8EQ5AJ20120326 last accessed 17 March 2014) (29 - Urban and Rural Population by State, http://www.census.gov/compendia/statab/cats/popula tion.html, last accessed March 17, 2014

[3] US Census Bureau, Urban and Rural Population by State, http://www.census.gov/compendia/statab/cats/popula tion.html, last accessed March 17, 2014

[4] Delta Airlines Brief History, 2013, http://edmaymgmt7160.blogspot.com/2013/01/deltaairlines-brief-history.html, last accessed March 17, 2014

[5] A Timeline of US Airline Merger History, 2013, http://petergreenberg.com/2013/08/19/a-timeline-ofus-airline-merger-history/, last accessed March 17, 2014

[6]

https://aspm.faa.gov/opsnet/sys/Default.asp, last accessed March 17, 2014

[7] Small Community Rural Air Service/Essential Air Service, Updated: April 25, 2013, http://www.dot.gov/policy/aviation-policy/smallcommunity-rural-air-service/essential-air-service, last accessed March 17, 2014 
2014 Integrated Communications Navigation

April 8-10, 2014 and Surveillance (ICNS) Conference 